Cuticular Hydrocarbons as Sex Pheromone of the Bee Colletes cunicularius and the Key to its Mimicry by the Sexually Deceptive Orchid, Ophrys exaltata

\author{
Journal Article \\ Author(s): \\ Mant, Jim; Brändli, Christoph; Vereecken, Nicolas J.; Schulz, Claudia M.; Francke, Wittko; Schiestl, Florian P. \\ Publication date: \\ 2005-08 \\ Permanent link: \\ https://doi.org/10.3929/ethz-b-000032171
}

Rights / license:

In Copyright - Non-Commercial Use Permitted

Originally published in:

Journal of Chemical Ecology 31(8), https://doi.org/10.1007/s10886-005-5926-5 


\title{
CUTICULAR HYDROCARBONS AS SEX PHEROMONE OF THE BEE Colletes cunicularius AND THE KEY TO ITS MIMICRY BY THE SEXUALLY DECEPTIVE ORCHID, Ophrys exaltata
}

\author{
JIM MANT, ${ }^{1}$ CHRISTOPH BRÄNDLI, ${ }^{1}$ NICOLAS J. VEREECKEN, ${ }^{1,2}$ \\ CLAUDIA M. SCHULZ, ${ }^{3}$ WITTKO FRANCKE, ${ }^{3}$ \\ and FLORIAN P. SCHIESTL ${ }^{1, *}$
}

${ }^{1}$ Geobotanical Institute, ETH-Zürich, Zollikerstrasse 107, 8008 Zürich, Switzerland

${ }^{2}$ Zoologie Générale et Appliquée, Faculté Universitaire des Sciences Agronomiques, Gembloux, Belgium

${ }^{3}$ Institute of Organic Chemistry and Biochemistry, University of Hamburg, Hamburg, Germany

(Received December 6, 2004; revised February 23, 2005; accepted March 21, 2005)

\begin{abstract}
Male Colletes cunicularius bees pollinate the orchid, Ophrys exaltata, after being sexually deceived by the orchid's odor-mimicry of the female bee's sex pheromone. We detected biologically active volatiles of C. cunicularius by using gas chromatographic-electroantennographic detection (GC-EAD) with simultaneous flame ionization detection. After identification of the target compounds by coupled gas chromatography-mass spectrometry (GC-MS), we performed behavioral tests using synthetic blends of the active components. We detected $22 \mathrm{EAD}$ active compounds in cuticular extracts of $C$. cunicularius females. Blends of straight chain, odd-numbered alkanes and (Z)-7-alkenes with 21-29 carbon atoms constituted the major biologically active compounds. Alkenes were the key compounds releasing mating behavior, especially those with $(Z)-7$ unsaturation. Comparison of patterns of bee volatiles with those of $O$. exaltata subsp. archipelagi revealed that all EAD-active compounds were also found in extracts of orchid labella. Previous studies of the mating behavior in C. cunicularius showed linalool to be an important attractant for patrolling males. We confirmed this with synthetic linalool but found that it rarely elicited copulatory behavior, in accordance with previous studies. A blend of active cuticular compounds with
\end{abstract}

* To whom correspondence should be addressed. E-mail: florian.schiestl@env.ethz.ch 
linalool elicited both attraction and copulation behavior in patrolling males. Thus, linalool appears to function as a long-range attractant, whereas cuticular hydrocarbons are necessary for inducing short-range mating behavior.

Key Words - Ophrys, solitary bee, sex pheromone, pollination by sexual deception, alkane, alkene, floral mimicry.

\section{INTRODUCTION}

Colletes cunicularius (L.) (Hymenoptera: Colletidae) is a solitary oligolectic bee that nests in aggregations and mates soon after emergence. Males display a competitive mate-searching behavior based on olfactory cues. Females dig their nest cavities up to $1 \mathrm{~m}$ deep in sandy soil and line the brood cells with a secretion of the Dufour's gland (Cane, 1981). Males emerge first and patrol along the nest entrances in search of a mate. Using olfactory cues, males are able to accurately locate preemergent virgin females and distinguish them from mated females (Bergström and Tengö, 1978; Batra, 1980; Cane and Tengö, 1981). However, patrolling males are also attracted to preemergent males (Cane and Tengö, 1981). Females emerging from their nests stimulate scramble competition among large numbers of competing males (Müller, 1991). C. cunicularius is active in early spring from March to May when few bees or other insect species are in flight and at a time that restricts its primary pollen source to the early flowering Salix (Amiet et al., 1999). Males die during April/ May, whereas females continue to provision nests until the end of May.

Previous studies on chemical communication in C. cunicularius concentrated on the effects of cephalic compounds, in particular linalool, because it is the major compound in the mandibular gland secretions of both sexes in all Colletes species examined (Bergström and Tengö, 1978; Hefetz et al., 1979; Cane and Tengö, 1981; Lindsley and Zavortink, 1997). In behavioral experiments, Cane and Tengö (1981) demonstrated that linalool acts as a pheromone that enhances attraction and directs local search behavior of patrolling males to emerging females. However, in these tests linalool rarely stimulated male excavating or pouncing (copulatory) behaviors. In contrast, head extracts of female C. cunicularius and even floral extracts of the orchid that mimics the female bees, Ophrys arachnitiformis-sphegodes, attracted more males, caused more local searching, and released more copulatory attempts than linalool alone (Cane and Tengö, 1981). The lack of full copulatory behavior and the occurrence of linalool in males as well as females led Cane and Tengö to suggest that the presence of linalool may function mainly as a long-range attractant or aggregation signal stimulating precopulatory behavior in males. They suggested that pouncing behavior and the ability of males to distinguish between virgin and mated females may involve other olfactory cues, such as 
long-chain hydrocarbons that are present in Colletes and have subsequently been shown to be active in other bee genera such as Lasioglossum (Ayasse et al., 1999) and Andrena (Schiestl et al., 2000).

Recently, Borg-Karlson et al. (2003) showed enantiometrically pure $(S)$ (+)-linalool to be the main mandibular gland constituent of males and females of C. cunicularius, although both enantiomers induced electrophysiological responses from male antennae. Virgin females and males contain similar amounts of $(S)-(+)$-linalool (mean $71 \%$ of cephalic pentane extracts), whereas mated females had reduced amounts (mean 47\%) (Borg-Karlson et al., 2003). Synthetic $(S)-(+)$-linalool attracted the highest number of male bees, followed by the racemate and $(R)-(-)$-linalool. Thus, $(S)-(+)$-linalool, present in $C$. cunicularius, was shown to be an important component of the mate attractant pheromone. The decrease in $(S)-(+)$-linalool in mated females was suggested to account for the loss of attractiveness of mated females to patrolling males. However, the role that other compounds might play in eliciting C. cunicularius mating behavior was not further discussed. The apparent simplicity in the chemical communication between sexes was posited to be a response to the low interspecific competition in chemical signals and to the harsh meteorological environment of the early European spring.

The mandibular glands of females are an important source of sex pheromones in eusocial stingless bees (Engels et al., 1990; Engels, 1993), bumble bees (van Honk et al., 1978), and carpenter bees (Gerling et al., 1989). However, recent studies indicate that male attractant pheromones can involve multiple compounds from cuticular as well as other glandular secretions (Ayasse et al., 2001). Studies on Andrena (Schiestl et al., 1999), Lasioglossum (Wcislo, 1987; Ayasse et al., 1999), Osmia (Ayasse and Dutzler, 1998), and Nomia species (Wcislo, 1992) have detected female sex pheromones consisting of compounds localized on the surface of the cuticle. In Lasioglossum zephryum (Halictidae), macrocyclic lactones produced by the Dufour's gland appear to function as a sex pheromone (Smith et al., 1985). However, behavioral tests using synthetic lactones did not elicit copulatory behavior. Examination of the related $L$. malachurum revealed that the Dufour's gland was not the sole source of sex pheromone activity (Ayasse et al., 1993). Rather, hydrocarbons, isopentenyl esters, and unsaturated macrocyclic lactones localized on the cuticle induced copulation attempts by males.

Cuticular hydrocarbons, although known to have a major function in desiccation resistance (Hadley, 1981), are also used as sex pheromones in many insect taxa, especially among Diptera (Howard, 1993; Singer, 1998). In Andrena bees (Andrenidae), species-specific blends of cuticular hydrocarbons function as sex pheromones attracting males (Schiestl et al., 2000; Schiestl and Ayasse, 2002). Chemical analysis of the floral odors of the orchid, Ophrys sphegodes, showed hydrocarbon patterns similar to those found in females of the pollinator 
species, Andrena nigroaenea (Schiestl et al., 2000). Behavioral tests confirmed that $O$. sphegodes precisely mimics the female bee's olfactory cues and sexually deceives the pollinating Andrena males and thereby avoids the provision of floral rewards.

In this study, we reexamined the sex pheromone of $C$. cunicularius, the pollinator of Ophrys exaltata Tenore ( $O$. arachnitiformis species group), a sexually deceptive orchid species from southern Italy (Paulus and Gack, 1990a,b; Delforge, 1994). Our objectives were to (1) identify all components of the female sex pheromone of $C$. cunicularius, (2) investigate differences in the patterns of volatiles between virgin and mated females, (3) examine the importance of different physiologically active compounds for male attraction, and (4) compare the pattern of physiologically active compounds in C. cunicularius with the volatiles of its orchid mimic, O. exaltata.

\section{METHODS AND MATERIALS}

Sample Collection. Virgin C. cunicularius females were collected during the early flight season in March at Neuhausen (Switzerland). Wherever a cluster of males with an attractive female in the center was detected, the female was separated from the males as fast as possible, placed in a Perspex vial, and kept in a chilled box. Mated females were collected after the disappearance of males in late April at Neuhausen. All sampled bees were freeze-killed on the day on which they were caught. A total of 56 virgin and 22 mated females as well as 10 males were collected. For cuticle extracts, the whole body was extracted in $400 \mu \mathrm{l}$ hexane for $1 \mathrm{~min}$., whereas for head extracts, the head was extracted in $150 \mu \mathrm{l}$ hexane for $24 \mathrm{hr}$.

For the orchids, 69 samples of $O$. exaltata subsp. archipelagi Gölz and Reinhard, representing a subsample of those individuals sampled by Mant et al. (2005) were collected at two nearby populations in Monte Gargano (southeastern Italy). The labella were extracted in $200 \mu \mathrm{l}$ hexane for $1 \mathrm{~min}$. All samples were stored at $-20^{\circ} \mathrm{C}$.

Gas Chromatographic Analysis with Electroantennographic Detection $(G C-E A D)$. Aliquots of $1 \mu$ of the cuticle extracts of virgin females were injected splitless at $50^{\circ} \mathrm{C}(1 \mathrm{~min})$ into an Agilent $6890 \mathrm{~N}$ gas chromatograph (Agilent Palo Alto, CA, USA) followed by programming to $300^{\circ} \mathrm{C}$ at $10^{\circ} \mathrm{C} \mathrm{min}{ }^{-1}$. The gas chromatograph (GC) was equipped with an HP-5 column $(30 \mathrm{~m} \times 0.32 \mathrm{~mm}$ diam $\times 0.25 \mu \mathrm{m}$ film thickness $)$ and a flame ionization detector (FID). Helium was used as carrier gas. A GC effluent splitter (SGE International Pty Ltd, Sydney, Australia) was used, and a portion of the eluate was added to a purified and humidified air stream, directed over the excised antenna of a male 
bee. The tip of the antenna was cut off, and the antenna was mounted between two electrodes using electrocardiograph gel. The electrode holding the base of the antenna was grounded. The distal end of the antenna was connected via an interface box (Syntech, Hilversum, the Netherlands) for signal transfer to a personal computer. EAD signals and FID responses were simultaneously recorded. Twelve GC-EAD runs were performed with antennae from six males to check the reproducibility of antennal responses.

Structure Elucidation. The structures of compounds that elicited GC-EAD responses were identified by coupled gas chromatographic-mass spectrometric (GC-MS) analysis and coinjection with authentic standards. Extracts were analyzed with an HP-5970 (Hewlett-Packard) gas chromatograph equipped with a DB-5 capillary column $\left(30 \mathrm{~m} \times 0.32 \mathrm{~mm}\right.$ diam) operated at $120^{\circ} \mathrm{C}$ for $30 \mathrm{sec}$, then $4^{\circ} \mathrm{C} \mathrm{min}^{-1}$ to $280^{\circ} \mathrm{C}$. Structure elucidation of individual compounds was based on GC-MS analysis (VG70/250 SE instrument, Vacuum Generators, Manchester, England, UK, linked to an HP-5890 GC; conditions as mentioned above). Mass spectra $(70 \mathrm{eV})$ were compared with those reported in the literature (McLafferty and Stauffer, 1989) and with those of authentic reference samples. Gas chromatographic retention times were checked by coinjection. Double bond positions in mono- and diunsaturated compounds were assigned according to Buser et al. (1983) and Dunkelblum et al. (1985). The stereochemistry of double bonds was determined by comparison of retention times using corresponding reference samples, including dimethyldisulfide (DMDS) derivatives, as the erythro- and threo-adducts could be separated by GC.

Synthetic Compounds. The following compounds were purchased from Aldrich: linalool, decanol, dodecanol, hexadecanol, eicosanol, tetradecanoic acid, hexadecanoic acid, oleic acid, linoleic acid, tetracosanoic acid, saturated hydrocarbons, (9Z)-tricosene, 1-alkynes. Aldehydes were prepared from commercially available alcohols by using Swern oxidation (Mancuso and Swern, 1981). Mass spectra of synthetic compounds matched the expected patterns (McLafferty and Stauffer, 1989) and GC retention times. Esters were prepared form the corresponding acid chlorides and the appropriate alcohols according to standard laboratory methods. Mass spectra of synthetic compounds matched the expected patterns (Francke et al., 2000) and GC retention times. Alkenes were prepared by Lindlar hydrogenation of the corresponding alkynes. In a typical synthesis, a 1-alkyne was coupled to a 1-iodoalkane according to Buck and Chong (2001). The crude product was purified by column chromatography (Merck silica 60, 120-400 mesh, hexane). Lindlar catalyst (440 mg) was added to a solution of $0.7 \mathrm{ml}(5.8 \mathrm{mmol})$ freshly distilled quinoline in $10 \mathrm{ml}$ hexane. After addition of $1.87 \mathrm{mmol}$ of the alkyne in $5 \mathrm{ml}$ hexane, hydrogenation was carried out for $4 \mathrm{hr}$ at room temperature and atmospheric pressure. Subsequently, the catalyst was filtered off, and the solvent was removed in vacuo. Chromatography on silica provided the pure $(Z)$-alkene in over 95\% yield and 
99\% chemical purity. Alkadienes were prepared from the corresponding alkadiynes by Lindlar hydrogenation. As an example, the synthesis of $(8 Z, 20 Z)$ nonacosadiene is described. The corresponding reaction scheme is shown in Figure 1.

\section{2-(10'-Bromodecyloxy)-tetrahydropyrane 1}

A solution of $1.47 \mathrm{ml}(16.3 \mathrm{mmol}) 2,3$-dihydro- $4 H$-pyrane in $10 \mathrm{ml}$ dichloromethane was added to a solution of $2.5 \mathrm{ml}$ (13.6 mmol) 10-bromodecan-1-ol 1 (Aldrich) and $51 \mathrm{mg}(0.27 \mathrm{mmol}) p$-toluene-sulfonic acid hydrate in $100 \mathrm{ml}$ dichloromethane, which was cooled to $-15^{\circ} \mathrm{C}$. The reaction mixture was stirred for $1 \mathrm{hr}$, and subsequently warmed to room temperature. After the addition of 75 $\mathrm{ml}$ hexane, $75 \mathrm{ml}$ of a saturated aqueous sodium carbonate solution were added. After separation, the aqueous layer was extracted three times with $50 \mathrm{ml}$ hexane. The combined organic layers were washed with brine, dried over magnesium sulfate, and concentrated in vacuo. The crude product was chromatographed on silica using hexane: ethyl acetate 15:1 (v:v). As a result, $3.25 \mathrm{~g} \mathrm{(10} \mathrm{mmol,} \mathrm{74 \% )}$ of 2-(10'-bromodecylocy)-tetrahydropyrane were obtained.

a) $\mathrm{DHP}, \mathrm{pTsOH} / \mathrm{CH}_{2} \mathrm{Cl}_{2}$

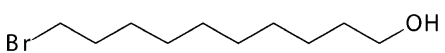

1

\section{b) Nal / acetone}

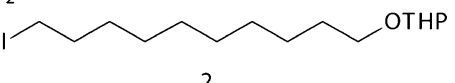

a) 1-nonyne, BuLi/THF b) $\mathrm{pT} \mathrm{sOH} / \mathrm{MeOH}$

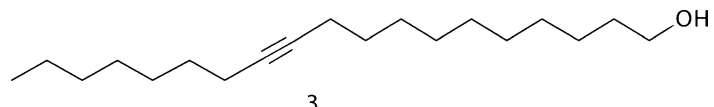

3

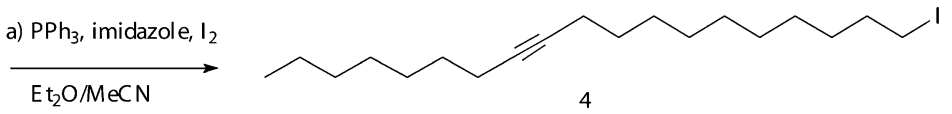

a) 1-decyne/B uLi

THF

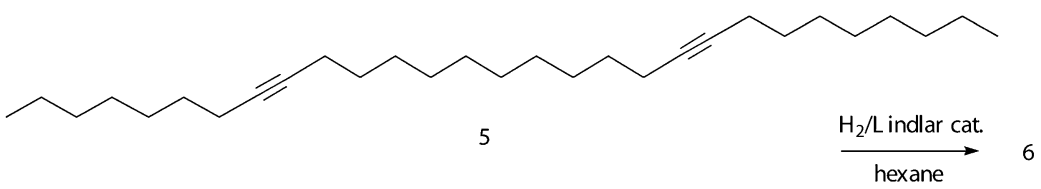

FIG. 1. Synthesis of $(Z 8, Z 20)$-nonacosadiene. 
${ }^{1}$ H NMR (400 MHz, $\left.\mathbf{C D C l}_{3}\right): \delta[\mathrm{ppm}]=1.27-1.72(\mathrm{~m}, 20 \mathrm{H}, \mathrm{H}-3-\mathrm{H}-5 /$ $\mathrm{H}-2^{\prime}-\mathrm{H}-8^{\prime}$ ), 1.84 (tt, 2H, $\left.J=7.12 \mathrm{~Hz}, \mathrm{H}-9^{\prime}\right), 3.40$ (t, 2H, $J=6.86 \mathrm{~Hz}, \mathrm{H}-10^{\prime}$ ), 3.48-3.55 (m, 1H, H-6a), $3.63\left(\mathrm{t}, 2 \mathrm{H}, J=6.61 \mathrm{~Hz}, \mathrm{H}-1^{\prime}\right), 3.82-3.89(\mathrm{~m}, 1 \mathrm{H}$, H-6b), 4.49-4.53 (m, 1H, H-2).

${ }^{13}$ C NMR (101 MHz, $\left.\mathbf{C D C l}_{3}\right): \delta[\mathrm{ppm}]=19.80 / 25.84 / 26.13 / 28.56 / 29.14 /$ 29.77/29.87/30.94/33.16/33.23/34.41 (t, C-3-C-5/C-2'-C-10'), 62.36/63.38 (t, C-6/ C-1' $), 100.12$ (d, C-2).

MS (70 eV): $m / z[\%]=322\left(0.74, \mathrm{M}^{+}\left(\mathrm{C}_{15} \mathrm{H}_{29} \mathrm{O}_{2}{ }^{81} \mathrm{Br}\right)\right), 320(0.72$, $\left.\mathrm{M}^{+}\left(\mathrm{C}_{15} \mathrm{H}_{29} \mathrm{O}_{2}{ }^{79} \mathrm{Br}\right)\right), 102(8), 101$ (8), 97 (10), 87 (25), 86 (96), 85 (100), 84 (11), 83 (18), 71 (9), 69 (21), 68 (8), 67 (10), 58 (11), 57 (42), 56 (30), 55 (46), 43 (32), 42 (17), 41 (52).

\section{2-(10'-Iododecyloxy)-tetrahydropyrane 2}

Sodium iodide $[2.23 \mathrm{~g}(15 \mathrm{mmol})]$ was added to a solution of $3.25 \mathrm{~g}$ (10 mmol) 2-(10'-bromodecyloxy)-tetrahydropyrane in $40 \mathrm{ml}$ acetone. The mixture was stirred for $12 \mathrm{hr}$ at room temperature. Subsequently, the solvent was removed in vacuo, and the residue was partitioned between $100 \mathrm{ml}$ water and $100 \mathrm{ml}$ of a 1:1 mixture of hexane and ethyl acetate. The organic layer was dried over magnesium sulfate, concentrated in vacuo, and directly used for the next step.

${ }^{1} \mathbf{H}$ NMR (400 MHz, $\left.\mathbf{C D C l}_{3}\right): \delta[\mathrm{ppm}]=1.26-1.72(\mathrm{~m}, 20 \mathrm{H}, \mathrm{H}-3-\mathrm{H}-5 /$ $\left.\mathrm{H}-2^{\prime}-\mathrm{H}-8^{\prime}\right), 1.82\left(\mathrm{tt}, 2 \mathrm{H}, J=7.63 \mathrm{~Hz}, \mathrm{H}-9^{\prime}\right), 3.19$ (t, 2H, $J=7.12 \mathrm{~Hz}, \mathrm{H}-10^{\prime}$ ), 3.48-3.55 (m, 1H, H-6a), $3.63\left(\mathrm{t}, 2 \mathrm{H}, J=6.61 \mathrm{~Hz}, \mathrm{H}-1^{\prime}\right), 3.82-3.89(\mathrm{~m}, 1 \mathrm{H}$, $\mathrm{H}-6 \mathrm{~b}), 4.49-4.53$ (m, 1H, H-2).

${ }^{13}$ C NMR (101 MHz, $\left.\mathbf{C D C l}_{3}\right): \delta[\mathrm{ppm}]=7.63\left(\mathrm{t}, \mathrm{C}-10^{\prime}\right), 19.77 / 25.85 /$ 26.13/26.62/28.91/29.74/29.77/30.17/30.89/30.94/33.17 (t, C-3-C-5/C-2'-C-9'), 62.36/63.40 (t, C-6/C-1' $), 100.20(\mathrm{~d}, \mathrm{C}-2)$.

MS (70 eV): $m / z[\%]=368\left(1.69, \mathrm{M}^{+}\right), 183$ (6), 102 (10), 101 (17), 97 (11), 87 (14), 86 (69), 85 (100), 84 (12), 83 (26), 71 (6), 69 (24), 68 (5), 67 (10), 58 (7), 57 (33), 56 (26), 55 (48), 43 (23), 42 (11), 41 (40).

\section{Nonadec-11-yne-1-ol 3}

A total of $6.7 \mathrm{ml}(10.7 \mathrm{mmol})$ of a $1.6 \mathrm{M}$ solution of $n$-butyl lithium in hexane were added dropwise to a solution of $1.94 \mathrm{ml}(11.7 \mathrm{mmol})$ non-1-yne in $100 \mathrm{ml}$ absolute $\mathrm{THF}$, cooled to $-78^{\circ} \mathrm{C}$. The mixture was warmed to room temperature within $4 \mathrm{hr}$, and $3.59 \mathrm{~g}(9.74 \mathrm{mmol})$ of 2, dissolved in $10 \mathrm{ml}$ hexane, were added. The mixture was refluxed for $12 \mathrm{hr}$. After cooling, $100 \mathrm{ml}$ of saturated aqueous ammonium chloride solution were added. After separation of the layers, the aqueous phase was extracted three times with $50 \mathrm{ml}$ of diethyl 
ether. The combined organic solutions were washed with brine, dried over magnesium sulfate, and concentrated in vacuo. The residue was dissolved in $50 \mathrm{ml}$ absolute methanol, and $0.5 \mathrm{~g} p$-toluene sulfonic acid hydrate were added. The mixture was stirred for $20 \mathrm{~min}$ at $50^{\circ} \mathrm{C}$. After cooling to room temperature, the solvent was removed in vacuo, and the residue was partitioned between $100 \mathrm{ml}$ diethyl ether and $100 \mathrm{ml}$ water. Subsequently, the aqueous layer was extracted three times with $50 \mathrm{ml}$ diethyl ether. The combined organic solutions were washed with brine and concentrated in vacuo. Purification was carried out by column chromatography using silica and hexane:ethyl acetate 10:1 (v:v). As a result, $2.06 \mathrm{~g}$ (7.35 mmol, 75\%) of nonadec-11-yne-1-ol 3 were obtained.

${ }^{1}$ H NMR (400 MHz, $\left.\mathbf{C D C l}_{3}\right): \delta[\mathrm{ppm}]=0.89(\mathrm{t}, 3 \mathrm{H}, J=6.61 \mathrm{~Hz}, \mathrm{H}-19)$, 1.28-59 (m, 26H, H-2-H-9/H-14-H-18), 2.13 (t, 4H, $J=6.86$ Hz, H-10/H-13), 3.63 (t, $2 \mathrm{H}, J=6.61 \mathrm{~Hz}, \mathrm{H}-1$ ).

${ }^{13}$ C NMR (101 MHz, $\left.\mathbf{C D C l}_{3}\right): \delta[\mathrm{ppm}]=14.48(\mathrm{q}, \mathrm{C}-19), 19.17 / 23.03 /$ 26.15/29.24/29.57/29.82/29.88/29.97/32.19/33.20 (t, C-2-C-10/C-13-C-18), 63.45 (t, C-1), 80.55/80.68 (s, C-11/C-12).

MS (70 eV): $m / z[\%]=280\left(0.07, \mathrm{M}^{+}\right), 138(23), 135$ (7), $124(6), 123$ (9), 121 (13), 111 (7), 110 (28), 109 (28), 108 (6), 107 (12), 98 (7), 97 (14), 96 (50), 95 (61), 94 (11), 93 (23), 91 (10), 85 (5), 83 (21), 82 (56), 81 (95), 80 (19), 79 (41), 77 (11), 70 (6), 69 (37), 68 (49), 67 (100), 66 (9), 65 (8), 57 (13), 56 (11), 55 (82), 54 (46), 53 (14), 43 (44), 42 (10), 41 (70).

\section{Nonadec-11-ynyliodide 4}

A total of $2.12 \mathrm{~g}(8.09 \mathrm{mmol})$ triphenyl phosphane and $0.55 \mathrm{~g}(8.09 \mathrm{mmol})$ imidazole were dissolved in a mixture of $60 \mathrm{ml}$ absolute diethyl ether and $20 \mathrm{ml}$ absolute acetonitrile. The mixture was cooled to $0^{\circ} \mathrm{C}$, and $2.05 \mathrm{~g}(9.09 \mathrm{mmol})$ iodine were slowly added. The mixture was stirred for an additional $20 \mathrm{~min}$ at $0^{\circ} \mathrm{C}$ and $2 \mathrm{hr}$ at room temperature. After cooling to $0^{\circ} \mathrm{C}, 2.06 \mathrm{~g}(7.35 \mathrm{mmol})$ of the ynol 3 were added. After additional stirring for $2 \mathrm{hr}$ at room temperature, $100 \mathrm{ml}$ water were added. After separation of the layers, the aqueous phase was extracted three times with hexane. The combined organic layers were washed with brine and dried over magnesium sulfate. Purification was carried out by column chromatography using silica and hexane:ethyl acetate 15:1 (v:v). As a result, $2.15 \mathrm{mg}$ ( $5.5 \mathrm{mmol}, 75 \%$ ) nonadec-11-ynyliodide 4 were obtained, which were used for the next step.

${ }^{1}$ H NMR (400 MHz, $\left.\mathbf{C D C l}_{3}\right): \delta[\mathrm{ppm}]=0.89(\mathrm{t}, 3 \mathrm{H}, J=6.87 \mathrm{~Hz}, \mathrm{H}-19)$, 1.20-1.51 (m, 24H, H-3-H-9/H-14-H-18), 1.82 (tt, 2H, $J=7.12$ Hz, H-2), 2.14 (t, 4H, $J=6.87 \mathrm{~Hz}, \mathrm{H}-10 / \mathrm{H}-13), 3.19$ (t, 2H, $J=7.12 \mathrm{~Hz}, \mathrm{H}-1)$.

${ }^{13}$ C NMR (101 MHz, CDCl 3 ): $\delta[\mathrm{ppm}]=7.67(\mathrm{t}, \mathrm{C}-1), 14.49(\mathrm{q}, \mathrm{C}-19)$, 19.17/23.04/28.94/29.23/29.52/29.56/29.59/29.78/29.84/30.91/32.19/33.98 (t, C-2-C-10/C-13-C-18), 80.61/80.70 (s, C-11/C-12). 
MS (70 eV): $m / z[\%]=390\left(1.28, \mathrm{M}^{+}\right), 196(6), 155$ (9), 137 (6), 124 (5), 123 (19), 111 (5), 110 (11), 109 (29), 97 (12), 96 (16), 95 (54), 93 (12), 91 (11), 83 (21), 82 (23), 81 (83), 79 (37), 77 (15), 69 (42), 68 (20), 67 (100), 65 (12), 57 (13), 56 (11), 55 (66), 54 (23), 53 (16), 52 (7), 43 (65), 42 (14), 41 (96).

\section{Nonacosa-8,20-diyne 5}

A solution of $0.28 \mathrm{ml}(1.54 \mathrm{~mol})$ 1-decyne in $30 \mathrm{ml}$ absolute THF was cooled to $-78^{\circ} \mathrm{C}$, and $0.8 \mathrm{ml}(1.41 \mathrm{mmol})$ of a $1.6 \mathrm{M}$ solution of $n$-butyl lithium in hexane was added. The stirred solution was warmed to room temperature within $3 \mathrm{hr}$. Subsequently, $0.5 \mathrm{~g}$ (1.28 mmol) nonadec-11-ynyliodide 4 was added, and the mixture was refluxed for $12 \mathrm{hr}$. After cooling to room temperature, $50 \mathrm{ml}$ saturated aqueous ammonium chloride solution were added. After separation of the layers, the aqueous solution was extracted three times with $30 \mathrm{ml}$ hexane. The combined organic layers were washed with brine, dried over magnesium sulfate, and concentrated in vacuo. Purification was carried out by column chromatography using silica and hexane. As a result, $312 \mathrm{mg}$ $(0.78 \mathrm{mmol}, 61 \%)$ of nonacosadiyne 5 were obtained.

${ }^{1}$ H NMR (400 MHz, CDCl $\left.\mathbf{~}_{3}\right): \delta[\mathrm{ppm}]=0.88(\mathrm{t}, 6 \mathrm{H}, J=6.86 \mathrm{~Hz}, \mathrm{H}-1 /$ H-29), 1.21-1.40 (m, 30H, H-2-H-5/H-12-H-16/H-24-H-28), 1.45-1.52 (m, 8H, H-6/H-11/H-18/H-23), 2.10-2.17 (m, 8H, H-7/H-10/H-19/H-22).

${ }^{13}$ C NMR (101 MHz, $\left.\mathbf{C D C l}_{3}\right): \delta[\mathrm{ppm}]=14.32 / 14.48(\mathrm{q}, \mathrm{C}-1 / \mathrm{C}-29)$, $19.24 / 23.10 / 23.18 / 29.01 / 29.21 / 29.26 / 29.32 / 29.71 / 29.98 / 30.02 / 30.05 / 32.18 /$ 32.25 (t, C-2-C-7, C-10-C-19/C-22-C-28), 80.42/80.72 (s, C-8/C-9/C-20/C-21).

MS (70 eV): $m / z[\%]=400\left(0.10, \mathrm{M}^{+}\right), 301$ (6), 287 (6), 203 (5), 189 (7), 175 (7), 161 (6), 149 (6), 147 (8), 135 (13), 133 (9), 123 (8), 122 (5), 121 (21), 119 (12), 110 (6), 109 (21), 108 (8), 107 (21), 106 (5), 105 (17), 97 (9), 96 (12), 95 (52), 94 (15), 93 (32), 92 (5), 91 (19), 83 (17), 82 (18), 81 (78), 80 (18), 79 (48), 77 (12), 71 (8), 70 (6), 69 (34), 68 (18), 67 (100), 66 (6), 65 (9), 57 (33), 56 (14), 55 (91), 54 (35), 53 (18), 52 (5), 43 (68), 42 (11), 41 (82).

\section{(8Z,20Z)-Nonacosadiene 6}

Sixty milligrams Lindlar catalyst (Lancaster) and $125 \mathrm{mg}(0.31 \mathrm{mmol})$ nonacosa-8,20-diyne 5 were added to a solution of $0.09 \mathrm{ml}(0.75 \mathrm{mmol})$ freshly distilled quinoline in $5 \mathrm{ml}$ hexane. Hydrogenation was carried out at room temperature and atmospheric pressure. After filtration, the solvent was removed in vacuo. Purification was carried out by column chromatography using silica and hexane. As a result, $117 \mathrm{mg}(0.29 \mathrm{mmol}, 94 \%)(8 Z, 20 Z)$-nonacosadiene were obtained. 
${ }^{1}$ H NMR (400 MHz, CDCl $): \delta[\mathrm{ppm}]=0.88(\mathrm{t}, 6 \mathrm{H}, J=7.12 \mathrm{~Hz}, \mathrm{H}-1 /$ H-29), 1.20-1.45 (m, 38H, H-2-H-6/H-11-H-18/H-23-H-28), 1.98-2.05 (m, 8H, H-7/H-10/H-19/H-22), 5.32-5.37 (m, 4H, H-8/H-9/H-20/H-21).

${ }^{13} \mathbf{C}$ NMR (101 $\left.\mathbf{M H z}, \mathbf{C D C l}_{3}\right): \delta[\mathrm{ppm}]=14.50(\mathrm{q}, \mathrm{C}-1 / \mathrm{C}-29), 23.08 /$ 25.74/27.62/29.63/29.68/29.73/29.97/30.19/32.29/32.32/32.88 (t, C-2-C-7, C-10C-19/C-22-C-28), 130.25/130.32 (d, C-8/C-9/C-20/C-21).

MS (70 eV): $m / z[\%]=404\left(0.87, \mathrm{M}^{+}\right), 152(5), 138$ (10), 137 (7), 125 (5), 124 (16), 123 (12), 111 (12), 110 (23), 109 (20), 97 (35), 96 (63), 95 (35), 84 (5), 83 (48), 82 (62), 81 (43), 80 (6), 79 (6), 71 (7), 70 (13), 69 (55), 68 (26), 67 (43), 57 (31), 56 (23), 55 (100), 54 (28), 53 (5), 43 (56), 42 (9), 41 (53).

Quantitative Analyses of GC Data. Gas chromatography was used for quantitative analysis of extracts of individual female bees and orchids, using the same parameters as for GC-EAD. For quantitative analysis, $n$-octadecane was added as an internal standard. Absolute amounts were calculated by dividing the peak area of each compound by the peak area of the internal standard and multiplied with the internal standard amount (head extracts $0.5 \mu \mathrm{g}$, cuticle extracts $1 \mu \mathrm{g})$. Means and standard deviations were calculated for all compounds within each group of samples (cuticle of virgin females, head of virgin females, cuticle of mated females, cuticle of males, labella of $O$. exaltata).

Behavioral Tests. Head extracts and cuticle extracts of ten bees were tested for their attractiveness during the 2003 season. All behavioral tests were performed at Neuhausen, Switzerland, except for tests with linalool, which were performed at a second $C$. cunicularius population site at Fussach, in western Austria. Dead male bees, made odorless by extraction with a mixture of hexane and dichloromethane for $24 \mathrm{hr}$, were used as dummies. For each 3-min test, $70 \mu \mathrm{l}$ of the head extracts and $200 \mu \mathrm{l}$ of the cuticle extracts were applied to a dummy. After the solvent had evaporated, the dummy was placed in a male patrolling area. Behavioral responses of $C$. cunicularius males were classified into two categories: (1) approach, a zig-zagging or undulating approach towards the scented source and (2) contact, either a short pouncing contact with the scented source or a longer contact involving copulatory behavior. To control for the effect of visual and tactile stimuli alone, odorless dummies were tested after every fifth test.

Bioassays with synthetic compounds were performed during the 2004 season using cylindrical, black plastic beads as dummies rather than dead, odorless males, but otherwise with unchanged conditions. A subtractive design was chosen to test the relative importance of various mixtures of active compounds. However, mixtures of only the 12 most abundant compounds were used because not all compounds were available as synthetic substances. The following mixtures were prepared and their attractiveness tested in comparison to controls: (1) 12 active compounds, (2) active alkenes, (3) active alkanes, 
(4) active (Z)-7-alkenes. Synthetic blends were tested that matched the mean relative amounts of compounds found in virgin females at the Neuhausen C. cunicularius population. The absolute amount used corresponded to that found in one individual female bee. One hundred microliter solutions of each blend were applied to the dummies. In addition, to investigate the behavioral effects of linalool, the attractiveness of linalool alone was tested and in a mixture including all 12 active compounds, using synthetic racemic linalool $(1 \mu \mathrm{g})$.

Statistical Analysis. To compare the relative amounts of odor compounds among groups Kruskal-Wallis tests were employed because variances were not homogeneous among groups. Mann-Whitney $U$ tests were used for a posteriori multiple comparison with a Bonferroni correction and the level of significance set to $P=0.05$ divided by the number of comparisons. To test for differences in male bee responses in the different behavioral experiments, either the $t$-test or Kruskal-Wallis test followed by Mann-Whitney $U$ tests with a Bonferroni correction were used, as for the GC data. All calculations, tests, and graphics were performed with the statistical package SPSS 11 (Brosius, 2002).

\section{RESULTS}

Attractiveness of Virgin Female Extracts. Head extracts and cuticle extracts elicited similar numbers of approaches by male bees (Figure 2). However, cuticle extracts were more attractive than head extracts as they elicited significantly more "contacts" than head extracts.

Electrophysiology (GC-EAD). Because head extracts elicited few contacts in the behavioral tests, GC-EAD was performed only with cuticle extracts. Using GC-EAD, we detected 22 electrophysiologically active peaks representing 24 compounds in the cuticle extracts of virgin C. cunicularius females (Figure 3 and Table 1). Two GC peaks that elicited antennal responses consisted of more than one compound: hexadecanal and isopropyl tetradecanoate (peak 2), and dodecyl tetradecanoate and decyl hexadecanoate (peak 17). As a conservative approach, we treated both compounds found within each peak as active. The most abundant of the 22-24 electrophysiologically active compounds found in the cuticle were straight chain, odd-numbered alkanes and alkenes with 21 to 29 carbon atoms. Other compounds included two esters (compound numbers 2 and 17) three aldehydes (numbers 2, 5, and 13), and a terpene, linalool. The active compound $\mathrm{A}$, which occurred in relatively small amounts, remained unidentified. The strongest reactions from male antennae were elicited by $(Z)-9$ and $(Z)$ 7-alkenes and alkanes (Figure 3).

Differences in Volatiles among Female and Male C. cunicularius. Cuticle extracts of virgin and mated females differed with respect to the quantities of several bioactive compounds (Table 1, Figure 4). Virgin female cuticle extracts 


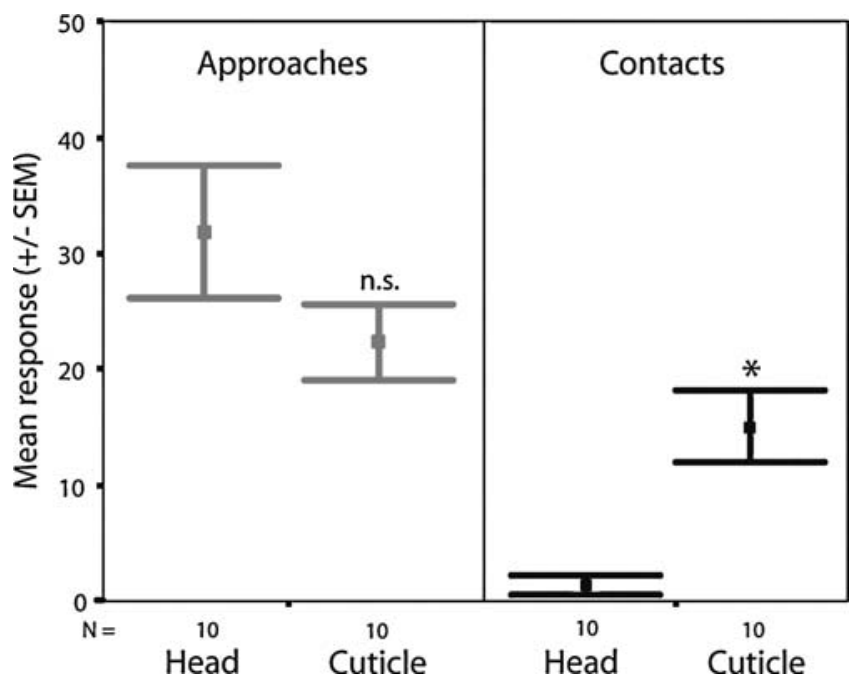

FIG. 2. Mean behavioral responses of $C$. cunicularius males exposed to head and cuticle extracts of virgin $C$. cunicularius females. Error bars are standard errors of means. Cuticle extracts elicited a similar number of approaches as head extracts $\left(t_{18}=1.44, P=\right.$ $0.17)$, but cuticles elicited more contacts than head extracts $\left(t_{10,4}=-4.3, P<0.01\right)$.

had significantly more linalool, $(Z)-7$-heneicosene, heptacosane, hexadecanal, and eicosanal than mated female cuticles. Virgin females had less (Z)-9heneicosene, dodecyl tetradecanoate, and decyl hexadecanoate.

Quantities of many compounds that did not elicit antennal responses also differed significantly between virgin and mated female cuticles. Three of these occurred in increased amounts in mated female cuticle extracts, namely, oleic acid (virgin cuticle $0.8 \%$ vs. mated female $27 \%)$, linoleic acid $(0.6 \%$ vs. $8.6 \%)$, and the unidentified compound U3 (1.2\% vs. $12 \%)$. These three compounds did not elicit EAD responses, but it should be noted that they were present only in small amounts in the virgin cuticle extracts used in the GCEAD experiments. As for the cuticle extracts, head extracts of virgins contained significantly more linalool and $(Z)-7$-heneicosene than head extracts of mated females.

In male cuticles, the most abundant compounds were alkanes with 21 to 29 carbon atoms and $(Z)-7$-heneicosene. In particular, the EAD-active compounds heneicosane, tricosane, and $(Z)-7$-heneicosene occurred in relatively high amounts (Table 1, Figure 4). Other EAD-active compounds occurred in extracts from males in only minor amounts.

Differences in Odor between C. cunicularius and O. exaltata. All 22 compounds detected in cuticle extracts of C. cunicularius that elicited EAD 


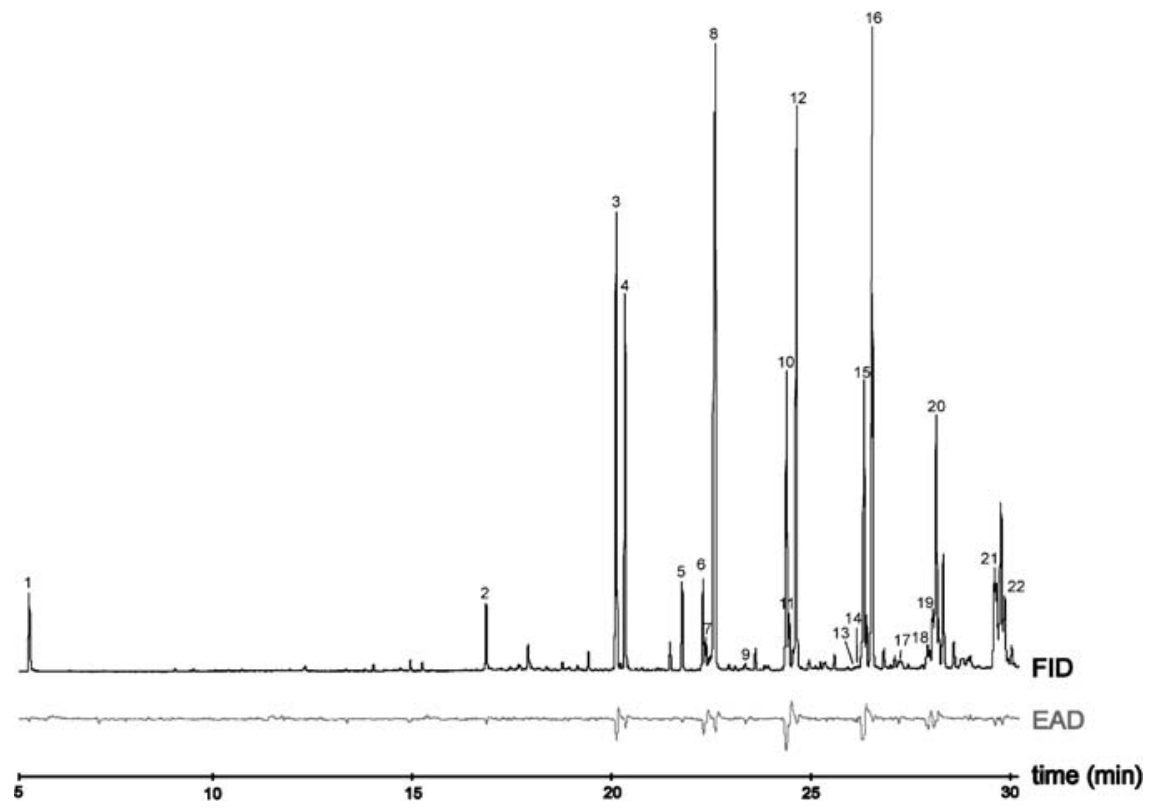

FIG. 3. Gas chromatographic analysis with electroantennographic detection (GC-EAD) of a cuticle extract of a virgin $C$. cunicularius female. Flame ionization detector and EAD responses were simultaneously recorded using an antenna of a $C$. cunicularius male. Numbered peaks correspond to compounds eliciting EAD responses. Compounds are listed in Table 1. Twelve GC-EAD runs were carried out with six males and the reproducibility of all responses at the same retention times was confirmed.

responses were found in the labellum extracts of $O$. exaltata subsp. archipelagi (Table 1, Figure 5). However, most of the compounds differed in their relative amounts between orchid and bee extracts (Figure 5). In particular, the (Z)-7-alkenes (C21, C23, C25) occurred in higher amounts in O. exaltata than in $C$. cunicularius females and, to a lesser extent, eicosanal and tetracosanal.

Behavioral Tests Using Synthetic Compounds. The first bioassay showed that linalool attracts patrolling males without eliciting corresponding contacts (pounces or attempted copulations) with the artificial odor source (Figure 6) (all tests using Mann-Whitney $U$ test, with $P<0.01$ ). The blend of 12 EAD-active odor compounds attracted a similar number of males to linalool alone, but elicited more contacts. When linalool was combined with the blend of active compounds, the number of males attracted was not different from the number attracted by linalool alone, but the number of contacts was higher than with the blend or linalool alone. 


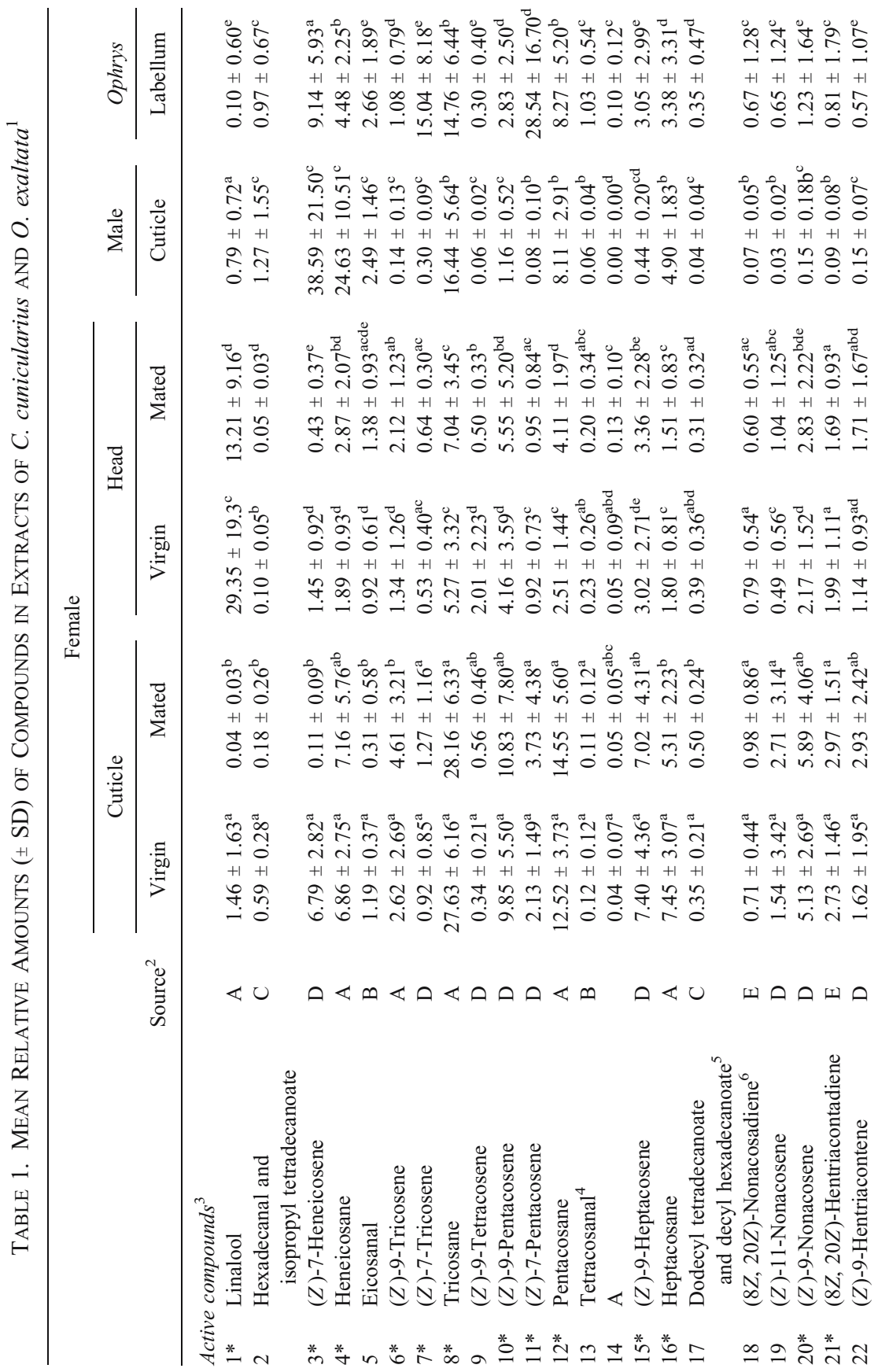


范

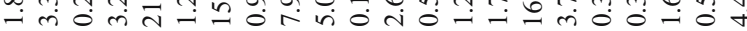
$+1+1+1+1+1+1+1+1+1+1+1+1+1+1+1+1+1+1+1+1+1+1$

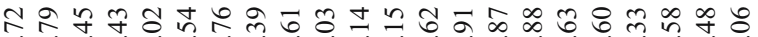
m००ण

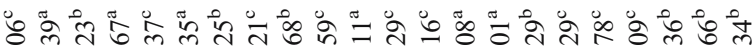
i

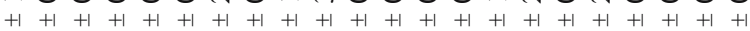
ڤึ)

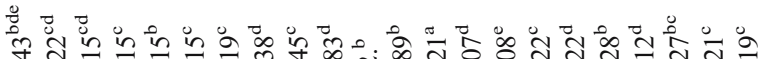

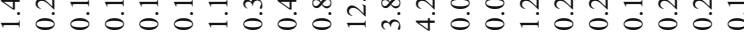
$+1+1+1+1+1+1+1+1+1+1+1+1+1+1+1+1+1+1+1+1+1+1$

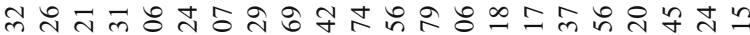

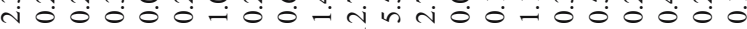

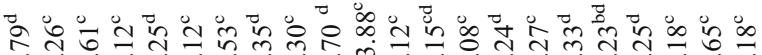

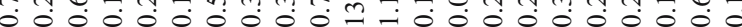
$+1+1+1+1+1+1+1+1+1+1+1+1+1+1+1+1+1+1+1+1+1+1$

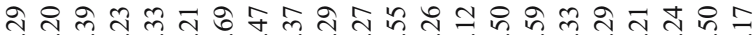

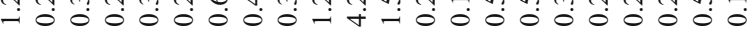

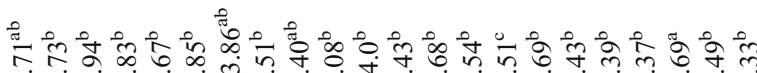

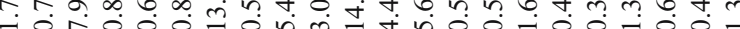
$+1+1+1+1+1+1+1+1+1+1+1+1+1+1+1+1+1+1+1+1+1+1$ ๙ m-

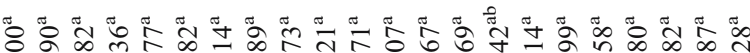

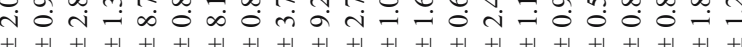
$+1+1+1+1+1+1+1+1+1+1+1+1+1+1+1+1+1+1+1+1+1+1$

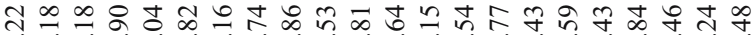

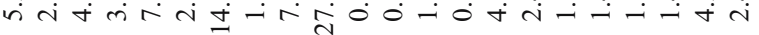

$\ll \cap \cap \ll \cap \ll \rho \ll \rho \ll \ll \ll$
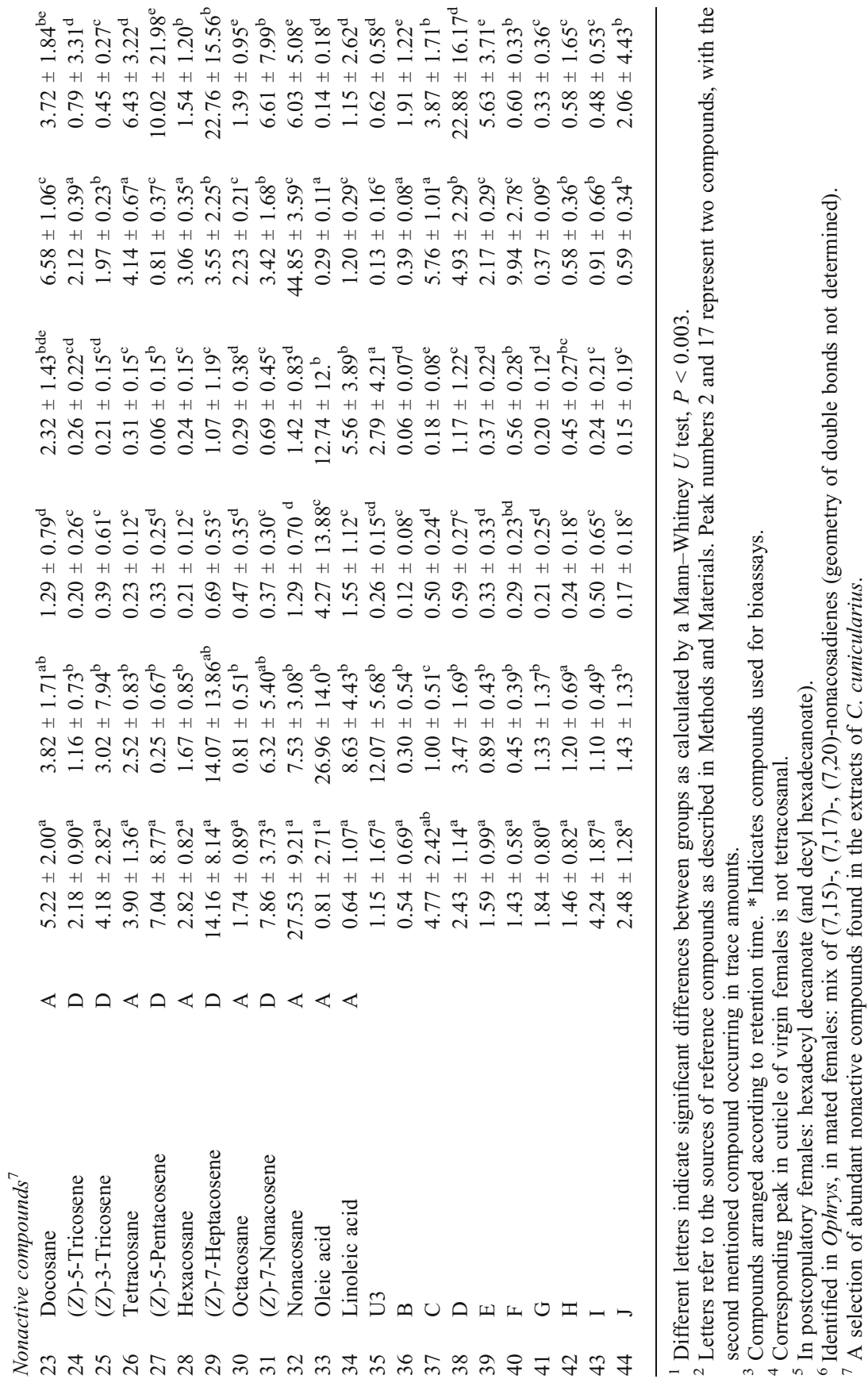


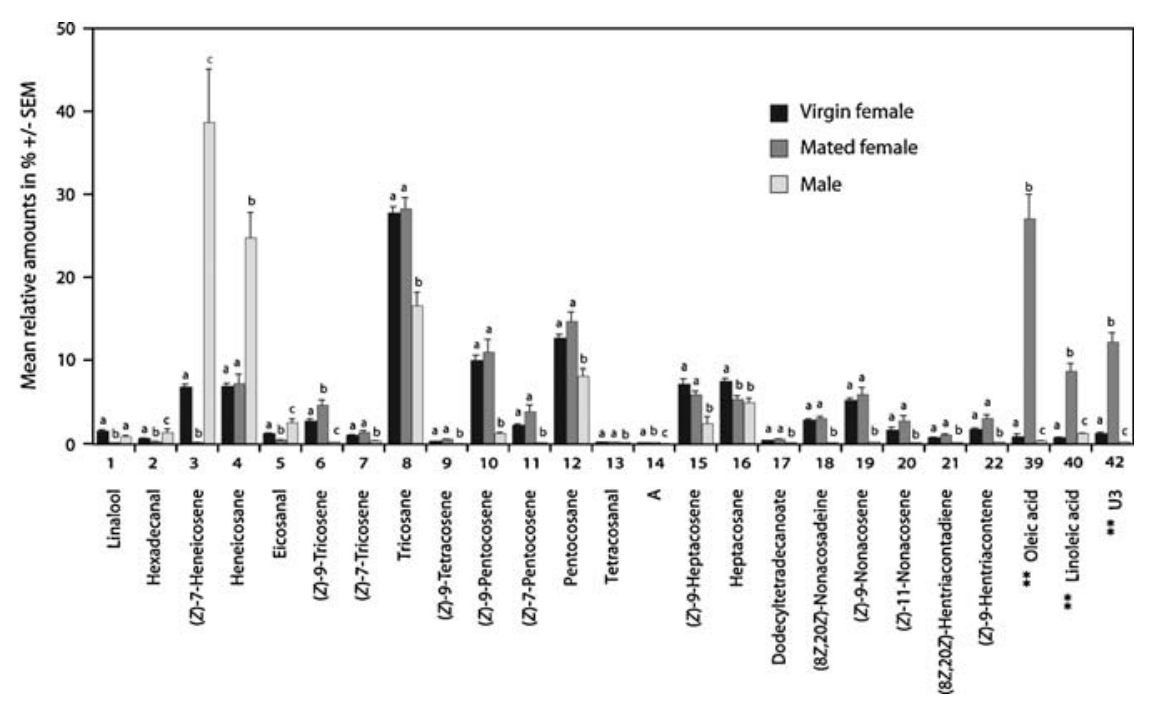

FIG. 4. Relative mean amounts of EAD-active compounds in cuticle extracts of males and virgin and mated females of $C$. cunicularius. Error bars are standard errors of means. Significant differences between groups for one compound are indicated by different letters according to Mann-Whitney $U$ test. For compounds numbers 2 and 17 please compare Table 1 for details.

Bioassays using various synthetic blends (Table 2 ) showed that the mixture of all 12 EAD-active hydrocarbons and the (Z)-7-alkenes induced similar numbers of attractions and contacts (Mann-Whitney $U$ test, with $P<0.005$, Figure 7). Behavioral responses to the mixture containing only alkenes were not different from the responses shown to (Z)-7-alkenes, but elicited fewer attractions or contacts than the 12-compound blend. Responses to alkanes were equivalent to responses to controls.

\section{DISCUSSION}

This study has shown that sex pheromone components of $C$. cunicularius are associated with the cuticle of virgin females and are also present in head extracts. GC-EAD experiments demonstrated that electrophysiologically active compounds include linalool and straight-chain, odd-numbered alkenes and alkanes with 21 to 29 carbon atoms. The attraction of males to a subset of these compounds was demonstrated in tests using synthetic compounds, confirming their function as attractant pheromones. 


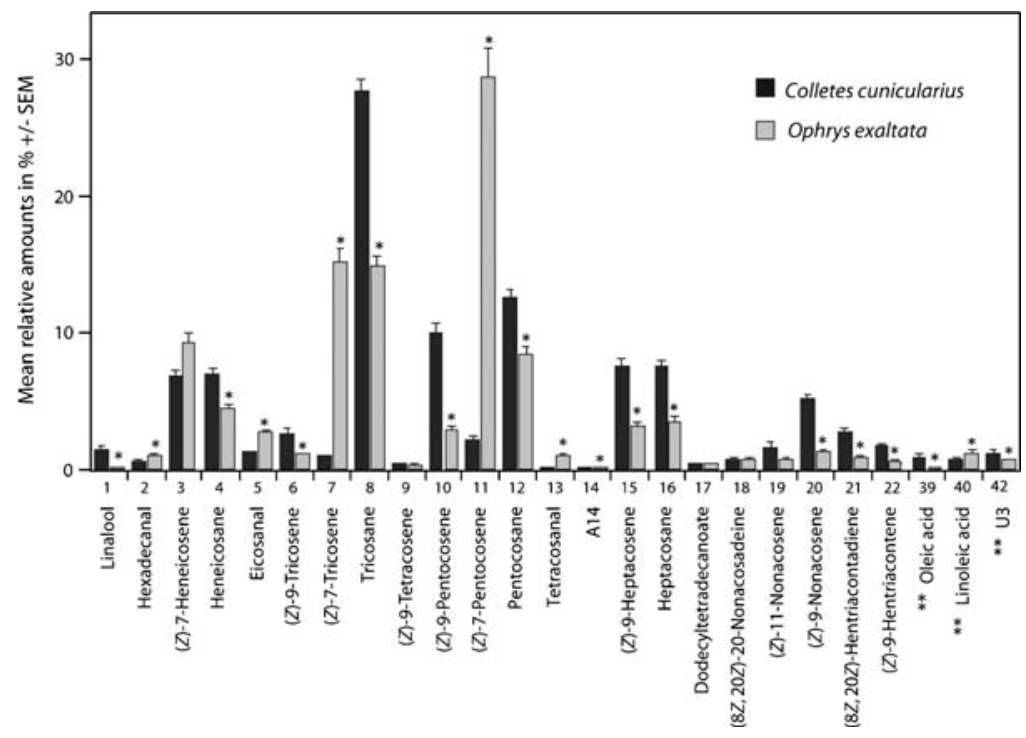

FIG. 5. Relative mean amounts of EAD-active compounds in cuticle extracts of virgin C. cunicularius females and labellum extracts of $O$. exaltata. Error bars are standard errors of means. Asterisk indicates significantly different relative amounts (see Table 1).

Linalool has previously been shown to have a sex pheromone function in C. cunicularius by its stimulation of an immediate increase in flight activity among patrolling males (Bergström and Tengö, 1978; Cane and Tengö, 1981; Borg-Karlson et al., 2003). Our study confirmed these earlier results by showing the attraction of patrolling males to synthetic linalool and to head extracts that contained high relative amounts of linalool. However, our behavioral tests also indicated that linalool alone rarely releases full mating behavior in males, consistent with previous findings (Cane and Tengö, 1981; Borg-Karlson et al., 2003). Head extracts containing high amounts of linalool elicited few contacts with the odor source, whereas this was frequently induced by cuticular extracts. Yet, more contacts were recorded with a mix of linalool and the blend of 12 active hydrocarbons than recorded with the blend of hydrocarbons or linalool alone. Presumably, the high amount of linalool in head extracts attracts patrolling males, whereas the relatively low amounts of other physiologically active compounds fail to trigger full mating behavior. These results lead us to support the contention of Cane and Tengö (1981) that linalool functions as a long-range sex attractant that enhances the onset of mating, whereas the presence of physiologically active cuticular hydrocarbons is necessary to induce copulatory behavior. 


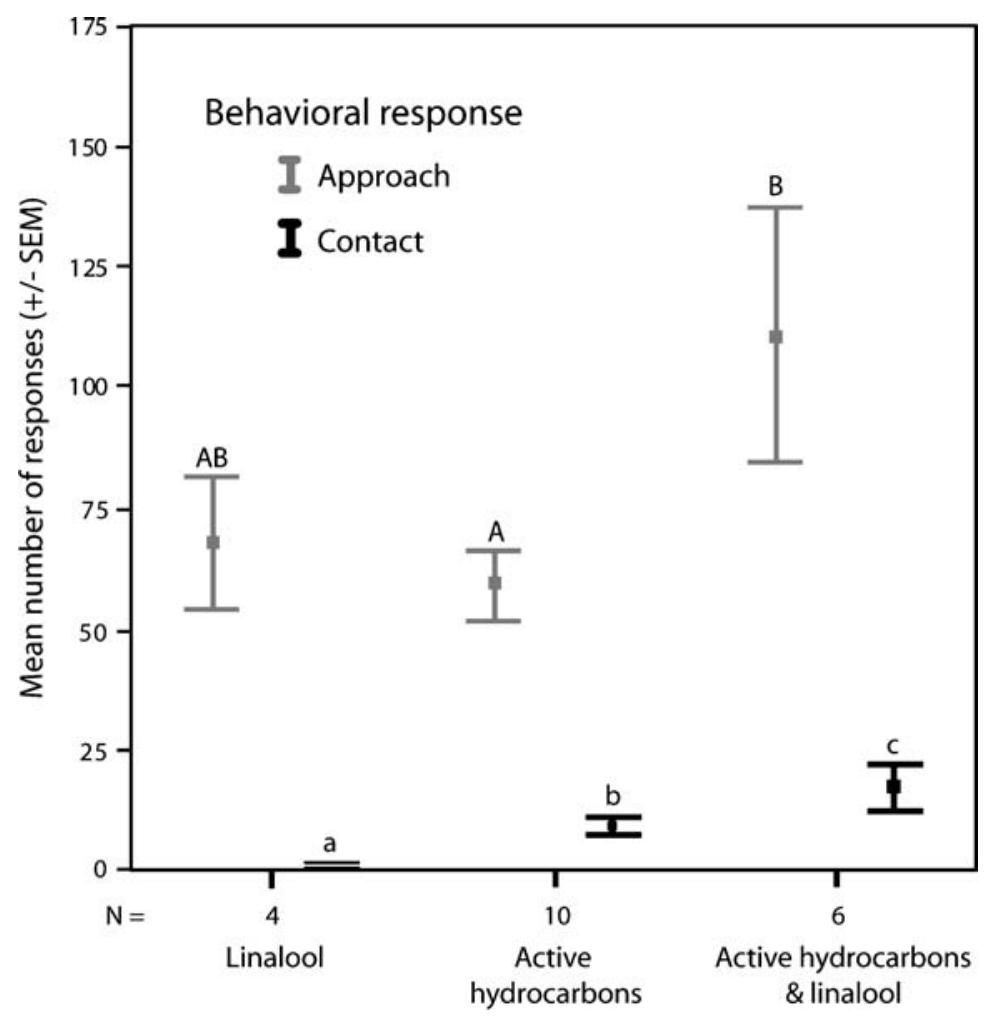

FIG. 6. Behavioral responses of C. cunicularius males to racemic linalool and a blend of EAD-active alkanes and alkenes (see Table 2 for blend composition). Different letters indicate significant differences among the test groups for "approaches" and "contacts" separately.

The behavioral tests with various subsets of the EAD-active compounds showed considerable differences in attractiveness to males. The most complete mixture of 12 compounds and the $(Z)-7$-alkenes were most attractive, followed by the blend of alkenes. The mixture of alkanes was not attractive (Figure 7). Interestingly, the mixture of 12 active compounds was more attractive than the full alkene blend, which suggests a synergistic effect among alkanes and alkenes, because the alkanes alone were not attractive. However, in our tests, there was a trend for the blend containing only (Z)-7-alkenes to be more attractive than the full alkene blend, suggesting that certain alkenes may inhibit the behavioral activity of the (Z)-7-alkenes. More behavioral tests are needed to confirm this. Generally, our results are similar to those from behavioral tests 
Table 2. Absolute Amounts $(\mu \mathrm{g})$ of Synthetic Compounds Used for Bioassays

\begin{tabular}{lccccc}
\hline \multicolumn{1}{c}{ Compound } & Colletes $^{\mathrm{a}}$ & $\begin{array}{c}\text { 12-Compound } \\
\text { blend }\end{array}$ & $\begin{array}{c}(Z)-7- \\
\text { Alkenes }\end{array}$ & $\begin{array}{c}\text { All } \\
\text { alkenes }\end{array}$ & $\begin{array}{c}\text { All } \\
\text { alkanes }\end{array}$ \\
\hline 1. (Z)-7-Heneicosene & 0.53 & 0.50 & 0.51 & 0.31 & - \\
2. Heneicosane & 0.53 & 0.60 & - & - & 0.51 \\
3. (Z)-9-Tricosene & 0.20 & 0.18 & - & 0.12 & - \\
4. (Z)-7-Tricosene & 0.08 & 0.09 & 0.08 & 0.18 & - \\
5. Tricosane & 2.29 & 2.37 & - & - & 1.77 \\
6. (Z)-9-Pentacosene & 0.80 & 0.86 & - & 0.52 & - \\
7. (Z)-7-Pentacosene & 0.18 & 0.21 & 0.20 & 0.10 & - \\
8. Pentacosane & 1.02 & 1.01 & - & - & 0.84 \\
9. (Z)-9-Heptacosene & 0.60 & 0.63 & - & 0.36 & - \\
10. Heptacosane & 0.58 & 0.64 & - & - & 0.54 \\
11. (Z)-9-Nonacosene & 0.41 & 0.35 & - & 0.21 & - \\
12. (Z)-8-(Z)-20-Hentriacontadiene & 0.21 & 0.12 & - & 0.12 & - \\
\hline
\end{tabular}

${ }^{a}$ Virgin female

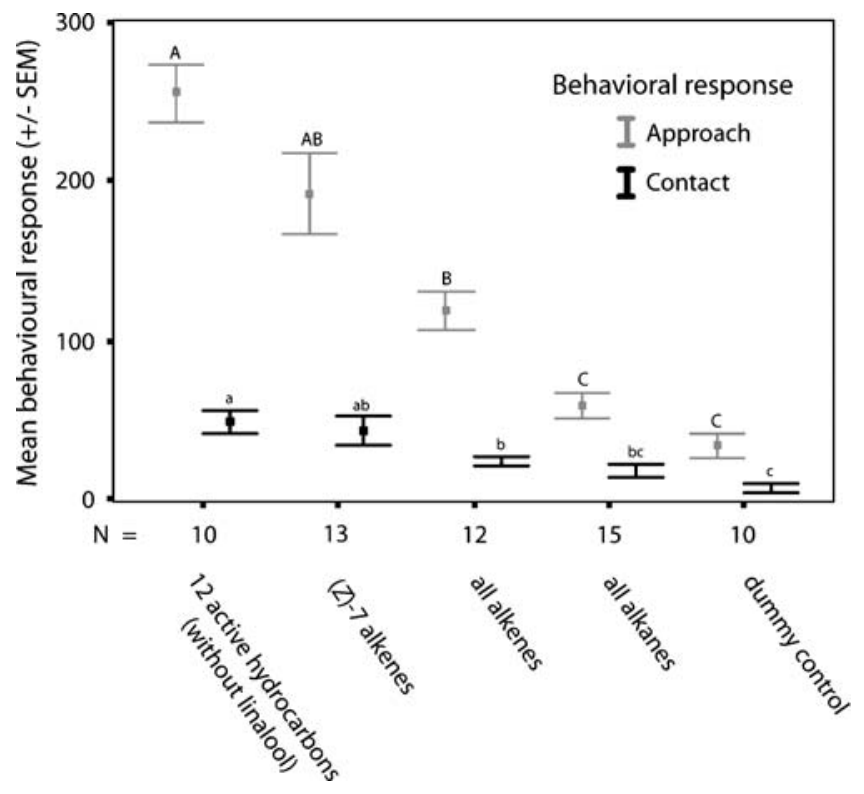

FIG. 7. Behavioral responses of C. cunicularius males to different blends of EAD-active compounds (see Table 2 for blend compositions). Different letters indicate significant differences among the synthetic mixtures for "approaches" and "contacts" separately. 
with $A$. nigroaenea in which blends of alkenes triggered approaches and contacts, whereas blends of alkanes were unattractive (Schiestl et al., 2000).

Avoidance of mated females by males has been suggested to be mediated by olfactory cues (Cane and Tengö, 1981). In the solitary bee, A. nigroaenea, the avoidance of mated females by patrolling males is due to an increase in farnesyl hexanoate, an antiaphrodisiac compound released from the Dufour's gland of mated females (Schiestl and Ayasse, 2000). The repellent compounds are also produced in pollinated flowers of $O$. sphegodes and may function to guide pollinators to unpollinated flowers within an inflorescence, thus increasing the reproductive fitness of the plant (Schiestl et al., 1997; Schiestl and Ayasse, 2001). In C. cunicularius, three compounds that increased markedly in cuticle extracts of mated females may also function as repellent or deterrent compounds, namely, oleic acid, linoleic acid, and the unidentified U3 (Figure 4). However, behavioral tests with these compounds have yet to be performed, and we did not detect male antennal responses to them.

The drop in male response to mated females could also be due to a reduction in the compounds that comprise the sex pheromone. Of the physiologically active compounds in cuticle extracts, linalool, $(Z)$-7-heneicosene and eicosanal, and to a lesser extent, hexadecanal and isopropyl tetradecanoate, decreased in mated females. Of these compounds, only linalool and $(Z)-7$ heneicosene showed a strong decrease also in head extracts of mated females in comparison to virgin ones. Thus, our behavioral tests, by highlighting the relative importance of $(Z)$-7-alkenes and linalool (Figures 6 and 7), support the suggestion that a reduction in $(Z)$-7-heneicosene and linalool contributes to a reduction in responses of males to mated females. Of note is that these two compounds are also present among the volatiles of males, with linalool being the most abundant compound in head extracts of males (Borg-Karlson et al., 2003) and ( $Z$ )-7-heneicosene the most abundant compound in cuticle extracts of males (Table 1). The observation that patrolling males were attracted to preemergent males as well as to preemergent females (Cane and Tengö, 1981) may be due to the production of $(Z)$-7-heneicosene and linalool by males.

Behavioral observations have shown that the orchid $O$. exaltata mimics the sex pheromone of $C$. cunicularius in a sexual deceit that leads to effective pollination by male bees (Kullenberg, 1961; Paulus and Gack, 1990b; Mant et al., 2005). Patrolling males are attracted to and attempt copulation with hexane extracts of the orchid labellum on dummies (Cane and Tengö, 1981; Mant et al., 2005). Our comparison of the labellum extracts of O. exaltata subsp. archipelagi and the cuticle extracts of virgin female C. cunicularius revealed all physiologically active compounds to be present in both organisms. This result is in accord with those obtained with the sexually deceptive $O$. sphegodes and its pollinator, A. nigroaenea (Schiestl et al., 2000). Both systems are consistent with the expectation of chemical mimicry in Ophrys pollination. 
However, the relative amounts of 19 of the 22 active compounds differed significantly between our $O$. exaltata and $C$. cunicularius extracts. In particular, $O$. exaltata showed higher relative amounts of (Z)-7-heneicosene, ( $Z$ )-7-tricosene, and $(Z)$-7-pentacosene, which we have shown to be key components of the sex pheromone of female C. cunicularius (Figure 5). The odor differences in the present study may be due to the geographic distance between the sampled populations of Colletes and Ophrys, the former from northern Switzerland, the latter from southern Italy (Mant et al., 2005). However, the pattern is also indicative of directional selection for higher production of key odor components, leading to a supernormal stimulus by the orchid, as suggested by Schiestl (2004) and Ayasse et al. (2003).

Acknowledgments - We thank Salvatore Cozzolino (University of Naples Federico II) for assistance, Andreas Müller (Zürich) for advice on local C. cunicularius populations, and the Museum of Natural History "Inatura," Dornbirn, for issuing collecting licenses. This study was funded by the Swiss National Fund Project 3100-068173, ETH-Zürich, and an Order of Leopold (ASBL), Belgium for N.J.V.

\section{REFERENCES}

Amiet, F., Neumeyer, R., and MÜller, A. 1999. Apidae 2. Schweizerische Entomologische Gesellschaft, Neuchâtel, Switzerland.

Ayasse, M. and DutZler, G. 1998. The function of pheromones in the mating biology of Osmia bees (Hymenoptera: Megachilidae). Social Insects at the Turn of the Millenium, Proc. Int. Congr. IUSSI, 13th. p. 42. Flinders University Press, Adelaide, Australia.

Ayasse, M., Engels, W., Hefetz, A., Tengö, J., LÜBKe, G., and FrancKe, W. 1993. Ontogenetic patterns of volatiles identified in Dufour's gland extracts from queens and workers of the primitively eusocial halictine bee, Lasioglossum malachurum Hymenoptera: Halictidae. Insect Soc. 40:1-18.

Ayasse, M., Engels, W., Lübke, G., Taghizadeh, T., and Francke, W. 1999. Mating expenditures reduced via female sex pheromone modulation in the primitively eusocial halictine bee, Lasioglossum malachurum (Hymenoptera: Halictidae). Behav. Ecol. Sociobiol. 45:95-106.

Ayasse, M., Paxton, R. J., and Tengö, J. 2001. Mating behavior and chemical communication in the order Hymenoptera. Annu. Rev. Entomol. 46:31-78.

Ayasse, M., Schiestl, F. P., Paulus, H. F., Ibarra, F., and Francke, W. 2003. Pollinator attraction in a sexually deceptive orchid by means of unconventional chemicals. Proc. R. Soc. Lond. Ser. B. 270:517-522.

BATRA, S. W. T. 1980. Ecology, behavior, pheromones, parasites, and management of the sympatric vernal bees Colletes inaequalis, C. thoracicus, and C. validus. J. Kans. Entomol. Soc. 53:509-538.

Bergström, G. and TenGÖ, J. 1978. Linalool in mandibular secretion of Colletes bees Hymenoptera: Apoidea. J. Chem. Ecol. 4:447-449.

Borg-Karlson, A.-K., Tengö, J., Valterová, I., Unelius, C. R., Taghizadeh, T., Tolasch, T., and FrANCKE, W. 2003. (S)-+-Linalool, a mate attractant pheromone component in the bee Colletes cunicularius. J. Chem. Ecol. 29:1-14. 
BRosius, F. 2002. SPSS Version 11. Mitp-Verlag, Bonn, Germany.

Buck, M. and CHONG, J. M. 2001. Alkylation of 1-alkynes in THF. Tetrahedron Lett. 42: $5825-5827$.

BUSER, H.-R., ARN, H., GUERIN, P., and RAUSCHER, S. 1983. Determination of double bond position in mono-unsaturated acetates by mass spectrometry of dimethyl disulfide adducts. Anal. Chem. $55: 818-822$.

CANE, J. H. 1981. Dufour's gland secretion in the cell linings of bees Hymenoptera: Apoidea. J. Chem. Ecol. 7:403-410.

CAne, J. H. and Tengö, J. 1981. Pheromonal cues direct mate-seeking behavior of male Colletes cunicularius Hymenoptera: Colletidae. J. Chem. Ecol. 7:427-436.

Delforge, P. 1994. Guide des Orchidées d'Europe d'Afrique du Nord et du Proche-Orient. Delachaux et Nestlé, Lausanne, Switzerland.

Dunkelblum, E., TAN, S. H., and SiLK, P. J. 1985. Double-bond location in mono-unsaturated fatty acids by dimethyl disulfide. Derivatization and mass spectrometry: Application to analysis of fatty acids in pheromone glands of four Lepidoptera. J. Chem. Ecol. 11:265-277.

ENGELS, W. 1987. Pheromones and reproduction in Brazilian stingless bees. Mem. Inst. Oswaldo Cruz Rio de Janeiro 823:35-45.

Engels, W., Engels, E., LÜBKe, G., SchröDer, W., and Francke, W. 1990. Volatile cephalic secretion of drones, queens, and workers in relation to reproduction in the stingless bee Scaptotrigona postica. Entomol. Gen. 15:91-101.

Francke, W., LÜbke, G., Schröder, W., Reckziegel, A., Imperatriz-Fonseca, V., Kleinert, A., Engels, E., HARTFelder, K., RAdKe, R., and Engels, W. 2000. Identification of oxygen containing volatiles in cephalic secretions of workers of Brazilian stingless bees. J. Braz. Chem. Soc. 11:562-571.

Gerling, D., Velthuis, H. H. W., and Hefetz, A. 1989. Bionomics of the large carpenter bees of the genus Xylocopa. Annu. Rev. Entomol. 34:163-190.

HAdLEY, N. F. 1981. Cuticular lipids of terrestrial plants and arthropods: A comparison of their structure, composition, and waterproofing function. Biol. Rev. 56:23-47.

HefetZ, A., BATRA, S. W. T., and BluM, M. S. 1979. Linalool, neral and geranial in the mandibular glands of Colletes bees - an aggregation pheromone. Experientia 35:320-321.

HowARD, R. W. 1993. Cuticular hydrocarbons and chemical communication, pp. 179-226, in D. W. Stanley-Samuelson and D. R. Nelson (eds.). Insect Lipids: Chemistry, Biochemistry and Biology. University of Nebraska Press, Lincoln, NE.

KullenBerg, B. 1961. Studies in Ophrys pollination. Zool. Bidr. Uppsala 34:1-340.

LindSLEY, E. G. and ZAVORTINK, T. J. 1997. Attraction of female Colletes louisae bees to netted, conspecific females (Hymenoptera Apoidea). Wasmann J. Biol. 35:144-148.

MANCUSO, A. J. and SwERN, D. 1981. Activated dimethyl sulfoxide: useful reagents for synthesis. Synthesis (3): 165-185

Mant, J., Peakall, R., and Schiestl, F. P. 2005. Does selection on floral odor promote differentiation among populations and species of the sexually deceptive orchid Ophrys? Evolution (in press).

McLafferty, F. W. and Stauffer, D. B. 1989. The Wiley NBS Registry of Mass Spectral Data. Interscience, New York.

MÜLlER, A. 1991. Wildbienen im Schafhauser Randen. Neujahresbl. Naturforsch. Ges. Schaffhausen 43:1-78.

PAULUS, H. F. and GACK, C. 1990a. Pollinators as prepollinating isolation factors: evolution and speciation in Ophrys Orchidaceae. Isr. J. Bot. 39:43-79.

Paulus, H. F. and GACK, C. 1990b. Zur Pseudokopulation und Bestäuberspezifität der Gattung Ophrys in Sizilien und Süditalien (Orchidaceae und Insecta Apoidea). Jahresber. Naturwiss. Ver. Wupp. 43:119-141. 
SCHIESTL, F. P. 2004. Floral evolution and pollinator mate choice in a sexually deceptive orchid. J. Evol. Biol. 17:67-75.

Schiestl, F. P. and AyAsse, M. 2000. Post-mating odor in females of the solitary bee, Andrena nigroaenea (Apoidea, Andrenidae), inhibits male mating behavior. Behav. Ecol. Sociobiol. 48:303-307.

SCHIESTL, F. P. and AYASSE, M. 2001. Post-pollination production of a repellent compound in a sexually deceptive orchid: a new mechanism for maximising reproductive success? Oecologia 126:531-534.

SChiestl, F. P. and AyAsSe, M. 2002. Do changes in floral odor cause speciation in sexually deceptive orchids? Plant Syst. Evol. 234:111-119.

Schiestl, F. P., Ayasse, M., Paulus, H. F., Erdmann, D., and Francke, W. 1997. Variation of floral scent emission and post pollination changes in individual flowers of Ophrys sphegodes subsp. sphegodes Orchidaceae. J. Chem. Ecol. 23:2881-2895.

Schiestl, F. P., Ayasse, M., Paulus, H. F., Löfstedt, C., Hansson, B. S., Ibarra, F., and FRANCKE, W. 1999. Orchid pollination by sexual swindle. Nature 399:421-422.

Schiestl, F. P., Ayasse, M., Paulus, H. F., Löfstedt, C., Hansson, B. S., Ibarra, F., and FRANCKE, W. 2000. Sex pheromone mimicry in the early spider orchid Ophrys sphegodes: patterns of hydrocarbons as the key mechanism for pollination by sexual deception. J. Comp. Physiol. A 186:567-574.

SingER, T. L. 1998. Roles of hydrocarbons in the recognition systems of insects. Am. Zool. 38: 394-405.

SMith, B. H., CARlson, R. G., and Frazier, J. 1985. Identification and bioassay of macrocyclic lactone sex pheromones of halictine bee Lasioglossum zephyrum. J. Chem. Ecol. 11: $1447-1456$.

VAn Honk, C. G. J., Velthuis, H. H. W., and RöSeler, P.-F. 1978. A sex pheromone from the mandibular glands in bumble-bee queens. Experientia 34:838-839.

WCISLO, W. T. 1987. The role of learning in the mating biology of a sweat bee Lasioglossum zephyrum Hymenoptera: Halictidae. Behav. Ecol. Sociobiol. 20:179-185.

WCISLO, W. T. 1992. Attraction and learning in mate-finding by solitary bees, Lasioglossum (Dialictus) figueresi Wcislo and Nomia triangulifera Vachal (Hymenoptera: Halictidae). Behav. Ecol. Sociobiol. 31:139-148. 